\title{
Reflections on the Status of the Field
}

\author{
Steven Rathgeb Smith, Executive Director, APSA
}

\begin{abstract}
A $s$ we approach the upcoming APSA Annual Meeting in Washington, DC, during Labor Day weekend, I am reminded in large and small ways that APSA is a different association than the one I joined in 1982: its membership has almost doubled in size; its membership and leadership are more diverse; its staff is larger (it's increased by about a third); and its structure is more complex since more than 40 organized sections have been added to the roster of standing committees. The addition of organized sections has expanded the number of disciplinary journals. The APSA Annual Meeting is much larger. When I joined the association the entire meeting could fit into the Washington Hilton, today we need three very large hotels. For the 2014 meeting, we received more than 15,000 submissions from more than 8,200 different individuals.
\end{abstract}

The social, political, and economic context of the association has shifted drastically since the 1980s. The number and scope of academic associations have increased. The digital revolution has affected associations. Social media has made it possible for research and teaching to reach a world-wide audience. The digital revolution is changing the way APSA members teach, and new innovations like massive open online courses (MOOCs) hold promise of reaching thousands of students. Open access publishing is growing in prominence and could even dominate the publishing field in the years to come. New online and/or open-access journals are being added.

Major changes in national public policy are also underway. An unpredictable future for federal support of political science, and the social sciences in general, lies ahead. Widespread pressure throughout the world is spurring political scientists and other scholars to adopt enhanced transparency in their research.
The demographic profile of the population and the students served by APSA members is changing rapidly. The association has responded with increased diversity in representation in APSA governance and leadership. While race, gender, ethnicity, and sexuality remain critical diversity issues, the complexity of the shifts within the association challenges the association to consider the different dimensions and perspectives on diversity and the implications for research, teaching, and representation in the association. Indeed, president-elect Rodney E. Hero has selected "Rethinking Diversities" as the theme of the 2015 APSA Annual Meeting. (Layna Mosely, University of North Carolina, Chapel Hill, and Alvin B. Tillery, Jr., Northwestern University, are the program co-chairs.)

All the changes have created new opportunities for the association. Organized sections and related groups are critical to the future of APSA. Many members increasingly identify with their section of interest-whether it is comparative politics, foundations of political theory, or one of the newer sections such as migration and citizenship. One challenge facing nonprofit organizations is to find ways to connect individuals with shared interests as the organization grows in scope and size. APSA and other academic associations are no exception. Many APSA members join more than one section reflecting their different interests with the association even as an individual member. The association also has more than 60 related groups that also help support members with very specific interests. We have a growing percentage of international members as well from a wide variety of countries.

The production and dissemination of knowledge are at the heart of political science. We cannot have dissemination of knowledge unless we have production of knowledge. Production occurs in a variety of ways, but largely through research by scholars whose work is written in the language of science, peer-reviewed, and published in academic journals. We know about the world around us from this process. Political science has increasing numbers of different types of journals and publications that are part of this production process. Dissemination happens through multiple outlets as well, perhaps most importantly in the classroom where political scientists educate and teach students-our future-with the knowledge produced by their research. Dissemination to the broader public occurs through a variety of traditional and new media. Blogs, for example, have become an important vehicle for the dissemination of research and information on the profession. Many faculty members have their own websites with postings about their most recent research including works in progress. The explosion in social media has encouraged political scientists to participate in the public sphere broadly defined through blogs, new online publications, Facebook, and Twitter, to name a few. Many political scientists from a variety of perspectives and subfields are participating in a wide array of public engagement activities.

This methodological diversity and public engagement also highlights the mistaken assumptions in Nicholas Kristof's op-ed essay from early 2014 in the New York Times. He suggested that political scientists were engaged in research that was inaccessible to the public and that they were no longer interested in real-world problems. Kristof seriously missed the mark. Political scientists, like other social scientists, are interested in the production of knowledge that may or may not have a direct impact on politics and public affairs. Moreover, methodological diversity of the profession has increased substantially during the last 30 years, with many new journals offering scholars of different methodological perspectives to publish their research. The growth of associations 
and conferences offers political scientists many more opportunities to share their work and network with scholars than in the 1980 . Social media has also created countless avenues for scholars to network and collaborate. And social media has also allowed political scientists to engage policy makers and the citizenry in new and different ways.

The very diversity of the political science profession raises the question of the commonalities among all its parts. One shared interest is teaching and the civic development of our students. The vast majority of the professional members of APSA are teaching students at institutions of higher education; even members whose primary employment is outside of the academy are often teaching as adjunct instructors. The APSA student members are either teaching already or likely to be teaching in the near future. Consequently, the quality of teaching and innovations in teaching and higher education is a high priority of APSA members. The association already offers its annual Teaching and Learning Conference held in the early part of the year. The next step is to develop more varied and extensive delivery of professional development and research material related to teaching and learning for our members. This effort could include more attention to teaching and learning within the context of the APSA Annual Meeting, support for professional development on teaching, more content about teaching and learning on the APSA website, collaboration with the APSA Organized Section on Teaching and Learning, and partnerships with other associations.

The membership of the association shares an interest in more transparency in research methods and inquiry. Regarding the latter, the APSA is co-sponsoring a conference at the University of Michigan in fall 2014 in connection with the ongoing data access and research transparency (DA-RT) project of the association. The goal is to develop research and publishing guidelines for the diverse methodological approaches within the association that will help inform practice, journal publishing, and public policy. The DA-RT project has already spurred the American Political Science Review (APSR) to change its editorial practices regarding research transparency. For example, by the time the manuscript is published in the journal, the underlying data and materials necessary to meet APSA's production and analytic transparency standards must be available in a trustworthy digital repository.

APSA members share an interest in civic education and fostering an engagement with local communities and the policy process. APSA members and the association more broadly can support more attention to effective civic education through research, teaching, and dissemination of promising and best practices. APSA members also have a shared interest in more public engagement by the association and its members, even if individual members may not be engaging the public directly. That is, the focus of many APSA members is properly on their research, and many political scientists undertake research that is not immediately relevant to public policy. But this does not diminish the importance of this research for the academy nor does it mean that the scholars are not interested in communicating their findings more broadly to the citizenry. The association can also assist with this communication through support for member engagement.

In sum, political science is an incredibly diverse, vibrant, and exciting discipline. Its members are producing important research that is enriching our understanding of the polity, international relations, community life, and the citizenry's engagement with the policy process. With the digital revolution, political science also has an opportunity to more fully develop and communicate important research to students, policy makers, and the citizenry. 